\title{
BRAILLE LITERACY LEVELS AMONG LEARNERS WITH VISUAL IMPAIRMENT IN SPECIAL SCHOOLS IN KENYA
}

\author{
Serah Wanjai, \\ Margaret Murugami, \\ Beatrice Bunyasi \\ Kenyatta University, \\ Nairobi, Kenya
}

\begin{abstract}
:
Effective education ensures that students are able to fully participate and benefit from it, regardless of whether they have impairments or not. Good vision is important for students at all stages of learning as it helps them reach their academic potential. It is paramount that students with visual impairment are proficient in Braille so that they are not disadvantaged academically since Braille remains their main medium of communication. Previous studies have ventured into academic performance of learners with visual impairment, however, nothing much is known about their Braille proficiency level. Braille reading tests were administered to forty-seven class eight and form four students in special schools for learners with visual impairments to establish their Braille literacy level. Semi structured interviews were used to solicit more information from four head teachers and a questionnaire used for sixteen teachers in the schools under study. Data was analyzed qualitatively along the common themes identified. The results established that Braille literacy level among primary school children was rather low. However, the case was quite different among high school students. There was no uniformity in the way schools arranged to teach their students Braille. Braille literacy could be improved if strategies were set to teach children with visual impairment Braille and ensure that they were proficient in it.
\end{abstract}

Keywords: Braille literacy, visual impairment, special schools, literacy level, NACOSTI, Kenya Institute of Special Education

\section{Introduction}

Relevance of Braille for learners whose vision is not adequate to read print comfortably has been highly recognised by experts in the field of education for learners with visual impairment (Castellano, 2010; Holbrook, 2009). Adults who have been denied an opportunity to learn Braille early in life have been found to have their success and

i Correspondence: email serawanjah@gmail.com 
confidence impacted on very negatively (Castellano, 2010). Early Braille learning has been linked with high academic achievement. To support this, Ryles (1997) carried out an investigation on literacy skills in grade 9-12 and compared the findings across four groups. The data was from 60 youths with 15 learners in each of the four groups. The first group comprised of youth with visual impairment who received regular Braille instruction during their primary grades for four to five times in a week. The second group were youths who received inconsistent Braille only two to three times per week. The third group were youths with visual impairment and received no instruction in Braille at all during their primary grades. The fourth group was made up of fully sighted learners who received print instruction on a regular basis of four to five times per week.

The findings indicated significant differences between the four groups on the Woodcock Jonson and Stanford Achievement Tests of Literacy. Learners with visual impairment who received Braille instruction for as many as four to five times in a week had achievement scores as high as those scored by those with full sight. More significant were results from those learners who received inconsistent or no Braille instruction at all. These learners were significantly behind their sighted peers and those with visual impairment (who received consistent instruction) as measured by the Woodcock Johnson. In addition, Bell, Ewell, and Mino (2013) found that all the youth who needed to use Braille but were not given any instruction in it were 1.5 years behind grade reading level after measurement by the Johns Inventory, whereas those who were receiving Braille instruction after they were assessed and confirmed to be in need of it were reading on same grade level with their sighted peers. The findings strongly support the need for early Braille instruction for learners with visual impairment.

In his qualitative study, Schroeder (1996) found that Braille literacy was very critical to the learners with visual impairment self-esteem and acceptance of their condition of vision loss. Moreover, Farrow (2015) reported that participants who learned Braille in adulthood increased their sense of independence in addition to accepting their condition of vision loss. A survey of 500 participants carried out by the National Federation of the Blind Jernigan Institute (2009) revealed a correlation between the ability to read Braille and a higher education level, higher possibility of employment and a higher income.

In technologically advanced world, the highly visual information reliance has impacted the development of social, cognitive, and linguistic structures (Hung, 2008). Literacy skills, thus, have become necessities to living more fully in the social, economic and political realms of mainstream society (Dunlea, 1989; Paul, 2001). However, unlike sighted individuals who take seeing for granted, those whose vision is limited must intensively work on realizing the unique quality of the simultaneity of information that sighted persons could obtain with ease (Hung, 2008). As sighted persons capture information and knowledge through print, the individual with visual impairment uses Braille to access information and communicates with others through Braille literacy (Hung, 2008). As a compensatory academic skill, Braille is the learners' major literacy medium, and as such it must be taught effectively by a competent teacher (Hatlen, 1997). 
It is essential for many learners that they have an aide or support person who is competent, enthusiastic and is highly committed to Braille (Gentle, 2000). In most cases this support person is the Braille transcriber and the Braille teacher. This is not the case in Kenya where a study by Nzoka (2011) found that learners with visual impairment were being taught by teachers who were not competent in Braille.

A study by the Canadian Braille Authority (2002) on the status of Braille literacy found that in Canada, Braille standards were really low. The study further concluded that there were no national standards for teachers of learners with visual impairment and also there were no educational prerequisites for these teachers (CBA, 2002). A similar study on Braille literacy by Corn and Koenig (2002) concluded that without appropriate instruction, learners with visual impairment maybe at risk for becoming low performing learners. The Canadian National Institute for the Blind (2014) noted that learners who do not read and write well have trouble succeeding in school and later in the work place. For learners whose eyesight prevents them from reading and writing print, Braille is the route to literacy. Further, CNIB observed that Braille is not hard to learn, especially when the student is young. Learners who learn Braille early usually become extremely fast and competent readers. Learners have an advantage over adults in that they learn more quickly, accept the tasks their teachers give them with little resistance, and expect to make mistakes as they go along. However, learning becomes more difficult when a child falls too far behind his or her classmates and feels discouraged and inferior (CNIB, 2014). Learners using Braille have been found to be slower in reading than those using print (Wall, Holbrook \& D'Andrea, 2009). These researchers found that learners who used print were about 1.5 to 2 times faster than those who used Braille.

On the Kenyan context, Kimeto (2010) carried out a study on challenges to effective learning of English Braille for pupils with visual impairment in integrated primary schools in Bomet district in Kenya. The study explored Braille reading levels of learners with visual impairment in class 3 to 5 and 6 to 8. It adopted a descriptive research design and targeted itinerant teachers, head teachers and teachers of Braille in the schools under study. The researcher presented 450 words to learners in class six to eight and out of the 450 words, the learners could not read 50 (11.1\%) words at all. 140 words $(31.1 \%)$ were read incorrectly and $260(57.8 \%)$ were read correctly. The situation was worse for learners in class three to five. These learners were able to read 150 (42.9\%) words out of the 350 words presented to them. $80(22.2 \%)$ words were read incorrectly and there was no attempt at all to read 120 (34.3\%) words (Kimeto, 2010).

\section{Methodology}

A qualitative study design was used to explore Braille literacy level of learners with visual impairments. The study participants were derived from four special schools for learners with visual impairments in Kenya. The learners were subjected to Braille reading tests to establish their individual reading levels. The reading tests were guided by the San Diego Quick Assessment of reading level and word recognition. The assessment has 
three levels according to the number of errors made. These are Independent level (1 error), Instructional level (2 errors) and frustration level (3 errors and above). The passages were in Braille grade 2. This means that they had full Braille contractions and Braille short forms. The learners were presented with passages to read aloud. Each incorrect response by the learners was recorded during administration and this assisted in placing them on different levels. In addition to checking the reading ability, the researcher also observed their reading styles, behavior and also recorded their reading speed. To supplement data collected through Braille reading tests, semi structured interviews were used to elicit more information from the head teachers and a questionnaire for the teachers. The interviews sought to find out the kind of strategies school administrations put in place to ensure that their learners were proficient in Braille. The questionnaire on the other hand, sought to find out from the teachers whether it was possible that students met new Braille signs they were not familiar with during examinations.

Consent to carry out the study was obtained from the National Commission for Science, Technology and Innovation (NACOSTI) through Kenyatta University. Since the study involved children below eighteen years, consent to subject them to the Braille reading test was sought from the head teachers. During the administration of the tests, the researcher was accompanied by the class teachers to help create rapport with the learners before the administration of the tests. The head teachers were contacted on phone individually to make prior arrangement on how and when to carry out the interviews. The interviews lasted between 35 to 40 minutes. They were recorded and later transcribed ready for the analysis.

\subsection{Data analysis}

Patterns in the data were identified by reading through and familiarizing with the interview data. Data was then coded and sorted into related themes. The interview transcripts were read, and key points summarized. Coding was done and sorted into common themes identified. Data was then analyzed along the themes identified. Data from the reading tests was sorted according to the three levels. Students were classified according to the number of errors made and placed in different levels accordingly. Further analysis was done on the reading speed, reading styles and other behaviors observed during reading.

\section{Findings}

\subsection{Braille literacy level of learners with visual impairment}

Learners' Braille literacy level was established through subjecting them to some Braille reading tests guided by the San Diego Quick Assessment of reading level and word recognition. The assessment was meant to give an idea of individual learner's reading level. The assessment had three levels according to the number of errors made. These were Independent level (1 error), Instructional level (2 errors) and frustration level (3 
errors and above). Each incorrect response by the learners was recorded during administration and this assisted in placing them on different levels. The learners were presented with passages to read aloud. The passages were in Braille grade 2. In addition to checking the reading ability, learners' reading speed, reading style and behavior exhibited while reading were recorded.

The learners were therefore guided to read the passages and were placed in any of the three levels according to the number of errors made. Figure 4.1 below presents the results. All the learners who were able to read Braille fluently were from secondary level and interestingly over half of the primary school learners were in the frustration level. In the independent level were 29 (90.62\%) of secondary school learners and $2(13.33 \%)$ of the primary level learners; instructional level had $3(9.37 \%)$ of the secondary learners and $5(33.33 \%)$ of the primary level learners. Frustration level had $0.0 \%$ of the secondary learners and 8 (53.33\%) of the primary level learners.

For confidentiality, easy identification and follow up of individual learner's reading ability, reading speed and any other relevant behavior observed, the learners were coded as either secondary learner 1(SL1) up to secondary learner 32 (SL32) or primary learner 1(PL1) up to primary learner 15 (PL 15) accordingly. The schools were coded as School 1, 2, 3 and 4 whereas the head teachers were labeled as Head teacher A $B, C$ and D.

Figure 1: Braille literacy levels

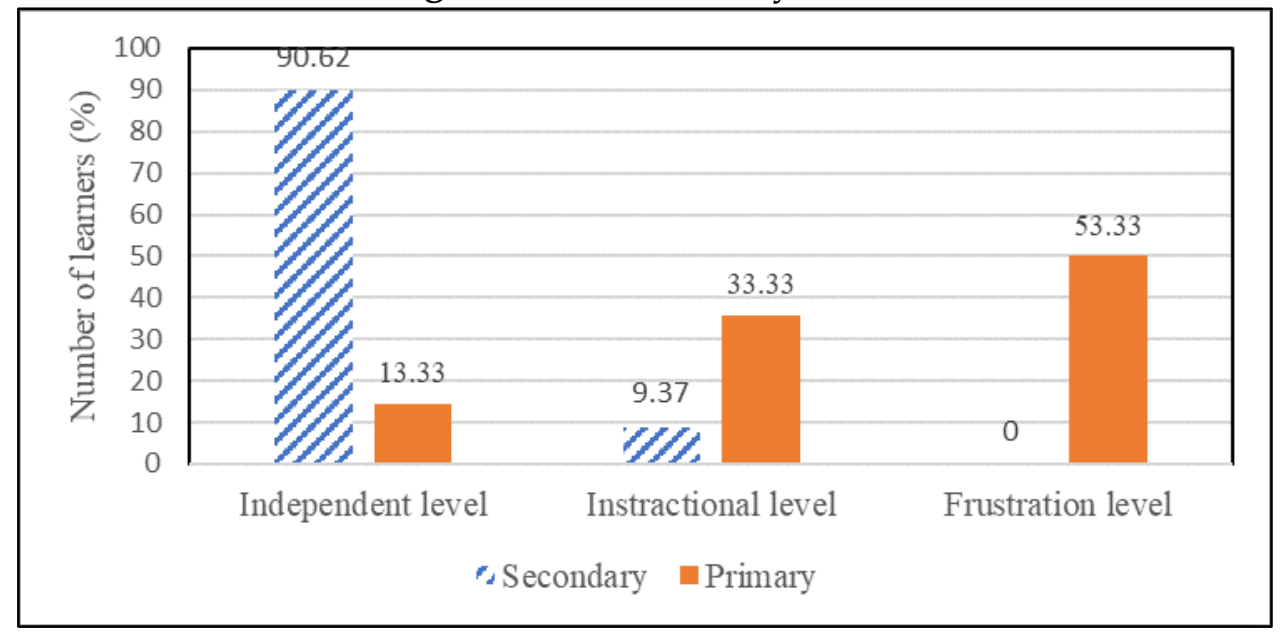

\subsubsection{Independent level}

In the independent level were a total of 31 learners. Of these 29 (90.62\%) were from secondary level and 2 (13.33\%) from the primary level. The figure indicates that majority of the secondary school learners (SL1upto SL29) were in the independent category according to the San Diego reading levels assessment. SL1 up to SL27 read fluently without missing a single word. This represented $81.0 \%$. Almost all the 27 learners read with 2 hands using four fingers. The left hand was almost in all cases used to establish the beginning of the new line as the right hand finished reading the preceding line. Apart from SL16 and SL 24 who bent over the reading material with stooping shoulders, all the 
rest sat upright as they read. In this independent level $3(9.0 \%)$ of the secondary school learners missed only a single word. These were SL27, SL28 and SL29. SL27 and SL28 could not read the word "several" correctly. SL29 missed the word "especially". She read the initial part of the word well but had a problem with the "...ally" contraction. The 'ally' part of this word is a composite sign in Braille which means that it involves use of more than one braille cell as opposed to simple signs which involve use of a single braille cell. It is among the final contractions. This might therefore imply that this learner had challenges with composite signs. The reading speed of SL1 up to SL29 was between 148 and 151 words per minute.

From the figure, a further $2(13.3 \%)$ of the primary school learners were in the independent level. These were PL1 and PL2. Both learners read fluently and quite fast. They made a single error each. Both had a good word attack and seemed to enjoy reading. PL1 missed the word "many" which is written as dot 456 M. PL2 seemed to have a problem with "and" when used as a group sign. Thus, in the word "husband", he managed to read the initial part of the word "husb" and struggled to read "and" without success. Both learners used four fingers of both hands in reading. PL1 read at a speed of about 144 words per minute and PL2 read at a speed of about 142 words per minute.

\subsubsection{Instructional level}

The findings further indicated that a minority of the secondary school learners, $3(9.37 \%)$ were in the instructional level. All the three, SL30, SL31 and SL32 missed two words each. SL30 and SL31 missed the words 'received' and 'behind' respectively. In addition, SL30 missed the word "several" and SL31 missed the word "singers". SL32 missed the word "yourself" which is a Braille short form written as "yrf". He also mispronounced the word "favorite". It is possible that these learners had challenges in both upper group signs and Braille short forms. Their reading speed was between 136 and 141 words per minute. They all spent a substantial amount of time rubbing over words they were not sure of. This finding supports Waterfied and West (2008) who concluded that learners who have not yet learnt contracted Braille should be given examinations in uncontracted Braille. The Results also shows that $5(33.33 \%)$ of the primary school learners were in the instructional level. These learners were PL3 through PL 7. They all made two errors each. Two of these learners had a reading speed of about 140 to 141 words per minute. They read with both hands and sat upright as they read through.

Both PL3 and PL4 mistook the word 'admission'. In this word the part 'sion' is a composite group sign among the final group signs. Just like the two primary school learners in the independent level; it is possible that the two had challenges with the final group signs in Braille. In addition, PL3 mistook the opening quotation marks for the word 'his'. The two are written with the same dot combination but 'his' is spaced from all other signs unlike the quotation sign which should be enjoined to the signs it follows. In addition to the word 'admission' PL4 missed the word "straight". He seemed to have a problem with the "ST" contraction. The other 3 learners, PL5, PL6 and PL7 had problems with short forms. PL5 and PL6 mistook 'received' and 'behind' which are shortened as 
'rcvd' and 'beh' respectively. In addition to the short forms, PL5 could not read the word 'many' just like PL1 in the independent level. PL6 and PL7 had problems with the words 'dialing' and 'office' respectively. They read at a speed below136 words per minute. PL6 read with the right hand resting his head on the left one.

\subsubsection{Frustration level}

It was interesting to note that there were no secondary school learners who fell in the frustration level. But surprisingly over half, 8 (53.33\%) of the primary school learners were all in the frustration level according to the San Diego assessment levels. These were PL8 to PL15. They could not read quite a number of words in the passage and their speed was also rather low. PL8 tried to use both touch and the little residual vision that he had. He would read with the fingers and then lift the material very close to the eyes may be to confirm what he had already read tactually. At some point he used only vision but managed to read just a few words with a lot of rubbing over. Use of both vision and touch would definitely slow his reading speed. He read at a speed of less than 50 words in a minute with a lot of skipping of words and rubbing over. A student reading at such a speed might not manage to complete his examinations considering that in Kenya, learners who use Braille are given an extra 30 minutes only in every examination (KNEC, 2013). Maybe that was one of the reasons why Carmen (2014) emphasized the need to provide learners with visual impairment double time for examinations to take care of such learners who are extremely slow in reading.

PL9 used one hand only. She kept on rubbing over the words and she would skip those words which may be seemed too difficult for her to read. She had problems reading even those words which did not have any Braille contractions. This finding revealed that the learner was not familiar with the Braille letters of the alphabet. PL10 read with his right index finger only with the other fingers hanging over the reading material. He seemed to get fatigued after a short while and would rest the hand on the material for a while before proceeding. He kept on losing his position. His reading speed was extremely low. He managed to read just a few words correctly. Such a learner would require time for rest breaks during examinations as observed by Carmen (2014). This finding also corroborates with (Rachel \& Douglas, 2015) whose study discovered that a number of learners were given rest breaks during examination due to fatigue.

PL11 and PL12 took almost a full minute before they started reading. PL11 kept on alternating the hands as she read though, one hand seemed more sensitive than the other. She kept her head tilted to the right as she read. PL12 kept on checking back. He would silently move the hand through a few words and then bring it back again and read the particular words loudly. Apart from the words they could not read, they also had challenges with punctuation signs. PL13, PL14 and PL15 were nonreaders. The worst scenario was PL15 who refused to read the material handed to him completely and declared that he did not know how to read English. This particular learner had multiple disabilities. Two of his fingers on the left hand were deformed in addition to his vision 
loss. Loss of fingers would interfere with his ability to read and also his reading style since the four fingers of both hands are very crucial in reading Braille.

Out of the forty-seven learners who were sampled for the study, only twentyseven $(57.44 \%)$ read the passage fluently without missing a single word. All the twentyseven were from secondary school level. Although $2(14 \%)$ of the primary school learners were in the independent level, none read fluently without missing a word. Just the same way most learners were not able to read all the words in the passages; it is possible that such a scenario can arise during examinations. New Braille words or signs that learners may come across when doing their examination would most likely put them in a disadvantaged situation.

\subsection{Braille reading styles}

There seemed to be no dominant style used by the learners when reading. They used different styles some of which seemed to affect their reading speed and others caused fatigue. All the twenty-seven secondary school learners and the two primary school learners in the independent stage used both hands using four fingers in each of the hand. Other learners used one hand (PL6 and PL9 in the instructional stage, with PL6 resting the head on the other hand). Another learner (PL1) kept on alternating the hands as she read through; she did not have a dominant hand. Yet another one (PL10) read with his right index finger only with the other fingers hanging over the reading material. The rarest scenario was observed on PL8 who used both touch and the residual vision in reading. May be to confirm with the eyes what she read tactually. This finding supports Shore and Klein (2001) who revealed that vision helps whenever there is some discrepancy between inputs from more than one channel.

\subsection{Teachers' responses on learners' Braille literacy level}

In order to elicit more information about the literacy levels of the learners, teachers were asked to indicate whether there were cases where learners met Braille signs which they were not familiar with in the KNEC examinations. Three quarters of them $(75 \%)$ indicated that it was possible that learners met some new Braille signs in the KNEC examinations. Most of these teachers were from the primary schools. A few teachers (25\%), most of who were from secondary schools agreed that there was no possibility that learners met any new Braille signs in the KNEC examinations. This finding is presented in Figure 2. 
Figure 2: Presence of new Braille signs in examinations

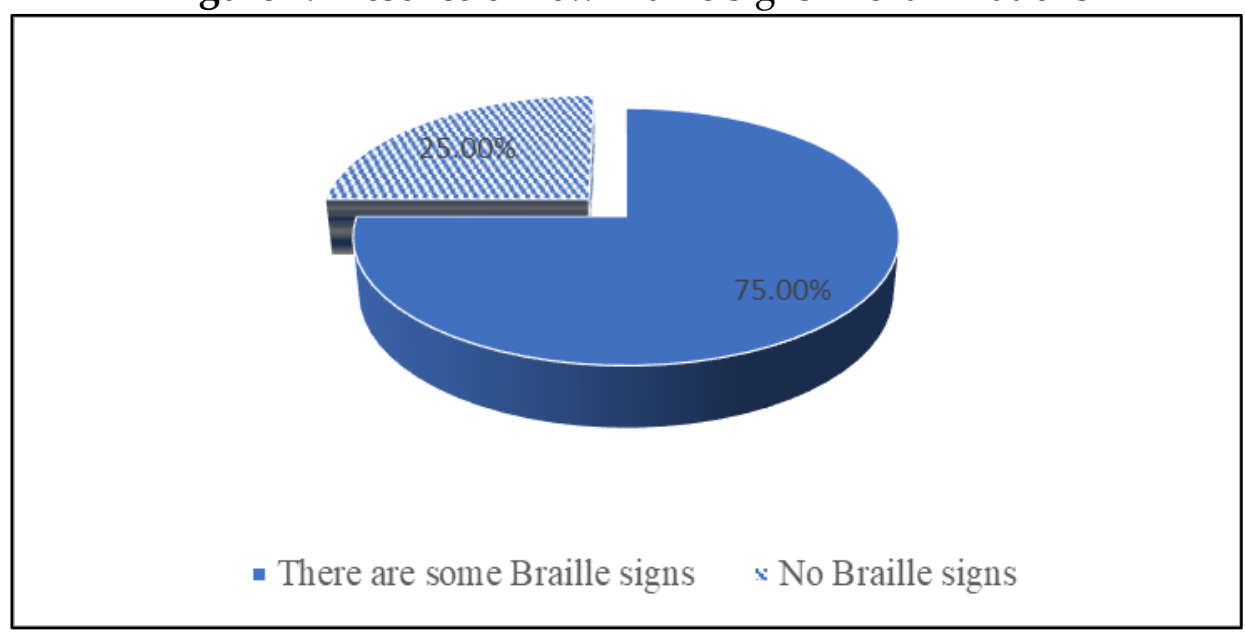

3.5 Teachers who realized the presence of Braille signs used in the KNEC examinations which learners might not be familiar with

Presence of new Braille signs in any examination would interfere with the ability to understand the question, statement or even instructions. Such a scenario can be compared to a situation where a sighted student meets a new word in an examination. In all the classes at primary level, the teachers noted that there were learners who were not competent in Braille. This supported the results from the Braille reading test which indicated that a big number of learners in the primary schools were not competent in Braille.

In order to assist those learners, the teachers organized to help them to improve on their Braille skills through different ways most of which were by; having Braille classes for beginners in situations where a student's vision worsened in the course of study $(75 \%)$, remedial and incorporating Braille lessons in normal learning like English, Kiswahili and Mathematics (60\%), conducting Braille literacy classes to intensify the teaching and learning of Braille and having school Braille policy (25\%). Other ways included encouraging the learners to team up with their peers who were good in Braille for peer tutoring (25\%). Some schools had assigned a group of teachers to assist the learners when out of class since Braille was not on the school time table. In addition, one of the schools sent such learners to learn Braille in rehabilitation institutions. Mostly such were learners whose vision deteriorated from low vision to total loss of vision within their course of study. However, such arrangements were only in some schools and not all.

\subsection{Head teachers' responses on learners' Braille reading ability}

In order to elicit more information about what informed the Braille literacy levels of the learners the head teachers were asked to explain how they ensured that their learners were competent in Braille through the interview schedule. Head teacher A had this to say about improvement of Braille literacy level of his learners, "Immediately learners with visual 
impairment are admitted in form one, they are taken through a very rigorous Braille proficiency assessment by a Braille proficiency panel set up by the school life."

The same head teacher was asked to explain how they ensured that all the teachers were proficient in Braille. He reported the following:

"Newly posted teachers who are not proficient in Braille are given strict timelines to learn it. The same seriousness applies to teacher trainees wishing to carry out any attachment in the school. Before they are allowed to practice, they are subjected to a thorough Braille proficiency assessment and failure to meet the set goals they are given time to improve on their skills within a period of two weeks. Failure to meet the expectation they are unfortunately denied the opportunity to practice in the school." (Head teacher, School A)

Head teacher B added that,

"Learners with visual impairment are disadvantaged when examinations are presented in a medium, they are not competent in. Sometimes it appears as if these learners are being tested for both Braille and the content in the subject areas, she added. In the event that a learner using Braille meets a Braille sign that they are not familiar with, they may fail, not because they do not know the correct response but due to the barrier imposed by Braille which they use to communicate."

On whether there were teachers in her school who were not proficient in Braille she replied "Oh yah, there are some teachers who join our school without knowing Braille but they learn it slowly and by and by they are able to use it well." Head teacher C further said, "Most of our learners experience many problems in writing and reading Braille since we do not teach it as a subject. We only correct errors they make in Braille when we mark their English and Kiswahili compositions." (Head teacher, School C). On teachers' Braille competency she reported that, "the good thing is that teachers of this school all know Braille because most of them have done special course."

Another head teacher gave her views on learners' levels of Braille proficiency, "Yes, some students are quite weak in Braille. Such are those who do not start school here." She was asked why this was the case. "When children are introduced to Braille learning at Pre School, they usually do well in it because they learn it early and get used to it. But some children join us in other classes after they lose their sight when they are big. There are also others who join our school with low vision and as time goes on, they lose their sight completely. Such children usually have problems in learning Braille. We help them by teaching them Braille whenever there is time." (Head teacher, D)

She was further asked to comment on the teachers' competency in Braille. "Our teachers know Braille since they hold Diploma certificates from the Kenya Institute of Special Education" 


\section{Discussion}

The findings from the interviews with the head teachers revealed that secondary school learners with visual impairment were more proficient in Braille than their primary school counterparts just as it was revealed by the Braille reading test results. At secondary level arrangements for teaching learners Braille were better organized than at the primary level. At secondary school level, schools came up with Braille policies which guided on how to ensure that learners not competent in Braille were subjected to rigorous practice until they were competent. This ensured that such learners were Braille competent by the time they were in form two and at most form three. It was also noted that at the secondary schools, learners had the advantage of practicing Braille during the time for subjects that they were not taking like Physics and chemistry. An observation of improved reading also suggested by Allman and Holbrook (1999) was that continued practice was associated with a lower number of errors.

The findings indicated that there were well organized strategies to teach Braille and there was also more practice at the secondary school level. The learners from these schools performed much better in the Braille reading test than those at the primary school level. In school 1, the administration went ahead and ensured that newly posted teachers who were not proficient in Braille were also given strict timelines to learn it as reported by head teacher A. The head teachers noted that if the learners with visual impairments were not competent in Braille, then there was no way they could perform well in their academic work.

In addition, the finding also supports Ritchie, Bates and Plomin (2015) whose longitudinal study found that children who were good in reading attained higher scores on general intelligence tests as compared to those who were not good in reading. This therefore implies that Braille incompetence could affect learners' performance in examinations. It also implies that a learner who is not assisted to learn Braille and master it properly is likely to miss out on properties of literacy that could propel intelligence, thus, resulting in low grades in examinations.

Out of the forty-seven learners who were sampled for the study, only twentyseven $(57.44 \%)$ read the passage fluently without missing a single word. All the twentyseven were from secondary school level. Although 2 (14\%) of the primary school learners were in the independent level, none read fluently without missing a word. Just the same way most learners were not able to read all the words in the passages; it is possible that such a scenario can arise during examinations. New Braille words or signs that learners may come across when doing their examination would most likely put them in a disadvantaged situation. This is because an unknown word or sign in a question or statement would hinder the particular student from getting the meaning and therefore respond incorrectly to the task at hand. This supports a case study by (Marietta Tanti Teaching, 2006) who noted that the use of Braille code as the medium to communicate mathematical work and the subsequent writing of results was invaluable. The finding further corroborates with more researchers (Frampton, 2006; Agrawal, 2004; 
Schleppenbach, 1997) who confirmed the importance of Braille proficiency in communicating mathematical work among other subjects.

\section{Conclusion}

Findings obtained showed that most form four learners were proficient in Braille. Most of them were rated as independent readers as opposed to class eight learners where most of them were found to be in the frustration level and thus not Braille proficient. These findings were derived from the Braille reading tests administered and also through interviews with the head teachers and questionnaire responses from the teachers. The findings also indicated that there was no uniformity in the way Braille was taught in the four schools under study. Some schools had Braille slotted on the regular school time table whereas in others Braille was taught outside the school time table.

There is need for uniformity in the way students with visual impairment are taught Braille across schools and ensure that they are proficient in it since it remains their main medium of communication.

\section{Conflict of Interest Statement}

The authors declare no conflicts of interests.

\section{About the Authors}

Serah Wanja is an assistant lecturer in the Department of Educational Psychology. She prepares student teachers to work with learners with visual impairment in Special schools and inclusive settings. She has published papers on learning resources and pedagogy in education for learners with visual impairment.

Margaret Murugami is a lecturer in the department of early childhood and special needs education, visual impairment section. She has published papers in the area of education for learners with visual impairment.

Beatrice Bunyasi is a lecturer in the department of early childhood, hearing impairment section. She has widely published papers in the area of special needs education and has supervised many post graduate students.

\section{References}

Agarwal, S. (2004). Teaching Maths to Blind learners through programmed learning Strategies. Abhijeet Publishers: New Delhi.

Allman, C. B. (2009). Test Access: Making tests accessible for learners with Visual Impairment: A guide for test publishers, test developers and state personnel $\left(4^{\text {th }}\right.$ edition.) Louisville, KT: American Printing House for the Blind. Retrieved from http://www.aph.org/tests/access2pdf. Retrieved on 22 ${ }^{\text {nd }}$ September 2017. 
Castellano, C. (2010). Getting ready for college begins in third grade: Working toward an independent future for your blind/visually impaired child. Charlotte, North Carolina: Information Age Publishing.

Bell, E. C., Ewell, J. V., \& Mino, N. M. (2013). National Reading Media Assessment: Complete Report. Journal of blindness, Innovation and Research, 3(2). Retrieved from https://nfb.org./images/nfb/publications/jbir/jbir13/jbir030201abs.html

Canadian Braille Authority. (2002). Standards for teachers of Braille reading and writing: Guide for presenters. Toronto, ON: Canadian National Institute for the Blind.

Carmen, W. (2014). Role of the classroom teacher. London: University of Roehampton Holbrook, M. C. (2009). Louis Braille Celebration: Supporting Students' Literacy through data-driven decision-making and ongoing assessment of achievement. Journal of Visual Impairment and Blindness, 103(3), 133-136

Corn, L., and Koenig, J. (2002). Literacy for Students with Low Vision. A Framework for Delivering Instruction. Journal of Visual Impairment and Blindness, 96, 305-321. https://doi.org/10.1177/0145482X0209600503

Dunlea, A. (1989). Vision and the emergence of meaning: Blind and Sighted Learners' early language. New York: Cambridge University Press.

Farrow, K. R. (2015). Using a group approach to motivate adults to learn Braille. Journal of Visual Impairment and Blindness, 109(4), 318-321

Frampton, M. (2006). Education of the Blind. A Study of Methods of Teaching Blind. Cosmo Publications: New Delhi.

Gentle, F. (2000). Braille Literacy: Report of an Australian National Survey of Braille. Teachers and support staff. Unpublished Paper. Sidney: Renwick College and St. Edmunds School for the blind and vision impaired.

Hatlen, P. (1997). The Core Curriculum for Blind and Visually Impaired Learners and those with Multiple Disabilities: Keynote Addresses. Papers Presented at the Conference of the Australia and New Zealand Association of Educators of the Visually Handicapped, Adelaide, Australia.

Holbrook, M. C. (2009). Louis Braille Celebration: Supporting Students' Literacy through data-driven decision-making and ongoing assessment of achievement. Journal of Visual Impairment and Blindness, 103(3), 133-136

Hung, Y. (2008). Teachers' Perspectives about Braille Literacy in Taiwan. Unpublished PhD Dissertation.

Kenya National Examinations Council (2013).

http://academics.uonbi.ac.ke/content.kenya-national-examinations-council.

Retrieved 17th October, 2018

Kimeto, A. C. (2010). Challenges to effective learning of English Braille for pupils with visual impairments in integrated primary schools in Bomet District, Kenya. Unpublished M. ed Thesis, Kenyatta University

Nzoka, M. Establishing Braille Proficiency levels among Primary School Teachers of Learners who are blind in Kenya. Unpublished PhD Research Thesis. Kenyatta University, 2011. 
Rachel, H. \& Douglas, G. (2015). Experiences of Blind and Partially Sighted Young Persons as they make the Transition into Higher Education. RNIB: Birmingham

Ritchie, S., Bates, T., and Plomin, R. (2015). Does Learning to read Improve Intelligence? A Longitudinal Multivariate Analysis in Identical Twins from Age 7 to 16. Journal of Childhood Development, XX, Volume 00, Number 0, pages 1-14.

Ryles, R. N. (1997). The relationship of reading medium to the literacy skills of high school students who are visually impaired. (Doctoral Dissertation). Retrieved from Proquest Digital Dissertations. (9819296).

Schleppenbach, D. (1997). Teaching Science to the Visually Impaired: The VISIONS Lab. The Braille Monitor Vol. 40 No 1 http://www.nfb.org.bm/bm97/brm970/htm.

Schroeder, F. K. (1996). Perceptions of Braille usage by legally blind adults. Journal of Visual Impairment and blindness, 90, 210-218

Wall, E., Holbrook, M. and D'Andrea, K. (2009). Acquisition of literacy skills by young children who are blind: Results from the ABC Braille study. Journal of visual impairment and blindness, 103(101), 610-624.

Waterfield, J. \& West, B. (2008). Meeting the Specific Requirement of Blind and Partially Sighted Learners Studying in Higher Education in the UK University of Plymouth. Plymouth: RNIB. 
Creative Commons licensing terms

Authors will retain the copyright of their published articles agreeing that a Creative Commons Attribution 4.0 International License (CC BY 4.0) terms will be applied to their work. Under the terms of this license, no permission is required from the author(s) or publisher for members of the community to copy, distribute, transmit or adapt the article content, providing a proper, prominent and unambiguous attribution to the authors in a manner that makes clear that the materials are being reused under permission of a Creative Commons License. Views, opinions and conclusions expressed in this research article are views, opinions and conclusions of the author(s). Open Access Publishing Group and European Journal of Special Education Research shall not be responsible or answerable for any loss, damage or liability caused in relation to/arising out of conflict of interests, copyright violations and inappropriate or inaccurate use of any kind content related or integrated on the research work. All the published works are meeting the Open Access Publishing requirements and can be freely accessed, shared, modified, distributed and used in educational, commercial and non-commercial purposes under a Creative Commons Attribution 4.0 International License (CC BY 4.0). 